\title{
Tendencias Recientes en la Producción, Comercio y Consumo de Mango en el Mundo y en los Estados Unidos ${ }^{1}$
}

Edward A. Evans ${ }^{2}$

\section{Introducción}

El mango se produce en más de 90 países. De la producción mundial, Asia produce el $77 \%$, las Américas el 13\% y Africa el 9\% (FAOSTAT 2007). Aunque no es el mayor productor de mango, los Estados Unidos ha desarrollado los cultivares comerciales más populares en el mercado internacional y es el país importador más grande del mundo. Este artículo resume algunas de las tendencias recientes en la producción, comercio y consumo de mango en el mundo y en los Estados Unidos.

\section{Producción, Importación y Consumo Mundial de Mango}

La producción estimada de mango en el 2005 fue de 28.51 millones de toneladas métricas. Entre 1996 y el 2005, la producción creció a un promedio del 2.6\%. El Cuadro 1 muestra los 10 países productores de mango más importantes del mundo, cuya producción representa el $85 \%$ del total mundial.
India es el productor más grande de mango, con el 38.6\% de la producción mundial en los años 2003 al 2005. Durante ese periodo, la cosecha de mango en India tuvo un promedio de 10.79 millones de toneladas métricas, seguida por China y Tailandia con 3.61 millones de toneladas métricas $(12.9 \%)$ y 1.73 millones de toneladas métricas (6.2\%), respectivamente. Otros productores importantes de mango durante el periodo 2003-2005, incluyen Méjico (5.5\%), Indonesia (5.3\%), Pakistán (4.5\%), Brasil (4.3\%), las Filipinas (3.5\%), Nigeria (2.6\%) y Egipto (1.3\%).

Aunque actualmente se comercia solamente el $3 \%$ de la producción mundial de mango, esto representa un incremento importante sobre las cantidades que se comerciaban hace 20 años. En lo que se refiere al mercado norteamericano, Méjico, Brasil, Perú, Ecuador, y Haití son los principales abastecedores. India y Pakistán son los abastecedores predominantes del mercado asiático occidental. Las Filipinas y Tailandia proveen principalmente al mercado asiático del sureste. La

1. Este es documento EDIS FE790, una publicación del Departamento de Food and Resource Economics, Florida Cooperative Extension Service, Institute of Food and Agricultural Sciences, University of Florida. Publicada en Noviembre 2008. La traducción del inglés al español estuvo a cargo de Carlos Jáuregui. Por favor, visite el sitio de EDIS en la red en http:edis.ifas.ufl.edu. English version (FE718).

2. Edward A. Evans, asistente profesor, Departamento de Food and Resource Economics, Tropical Research and Education Center, Homestead, FL, Florida Cooperative Extension Service, Institute of Food and Agricultural Sciences, University of Florida, Gainesville, FL.

El Instituto de Alimentos y Ciencias Agrícolas es un empleador que opera bajo Acción Afirmativa y provee Oportunidades Igualitarias, autorizado a proveer investigación, información educativa y otros servicios, únicamente a los individuos e instituciones que operan sin discriminación alguna con relación al credo, color, religión, edad, incapacidad, sexo, orientación sexual, estado civil, nacionalidad, opinion política o afiliaciones. Para más información sobre como obtener otras publicaciones de extensión, comuníquese con la oficina de Servicio de Extensión de su condado. Servicio de Extensión de la Florida / Instituto de Alimentos y Ciencias Agrícolas / Universidad de la Florida / Larry Arrington, Decano. 
Unión Europea compra mangos principalmente de Sudamérica y Asia.

En el 2005, las exportaciones mundiales de mango alcanzaron 912,853 toneladas métricas, por un total de 543.10 millones de dólares americanos (FAOSTAT 2007). El Cuadro 2 muestra los 10 principales países exportadores de mango. India reemplazó a Méjico en el 2005 como el productor más grande de mango. En el periodo 2003-2005 Méjico e India dominaron el mercado de exportación con el $22.6 \%$ y el $20.3 \%$ del total, respectivamente, seguidos por Brasil (13.2\%) y Pakistán (6.9\%). Otros exportadores importantes, incluyen Holanda (gran reexportador), Perú, Ecuador, las Filipinas, Tailandia, y China.

Las importaciones mundiales de mango se incrementaron de 397,623 toneladas métricas en 1996 a 826,584 toneladas métricas en el 2005. Como el importador número uno de mangos en el periodo 2003-2005, los Estados Unidos importó 271,848 toneladas métricas, o aproximadamente un tercio del total de las importaciones de mango (El Cuadro 3).

Holanda importó 88,300 toneladas métricas de mango (10.6\%), pero la mayoría de este volumen fue redistribuido a través de la Unión Europea. Otros importadores grandes que redistribuyen son los Emiratos Arabes Unidos (6.8\%) y Arabia Saudita (5.3\%), con la mayoría de sus importaciones redistribuidas a través del Medio Oriente. Las importaciones chinas de mango han estado declinando debido al incremento de la producción doméstica. Por ejemplo, en el 2004 China importó 57 toneladas métricas pero en el 2005 importó solamente 19 toneladas métricas. Otros importadores dignos de mencionar son Bangladesh, el Reino Unido (ambos con 4.6\%), Alemania (4.1\%), Francia (4.1\%), y Malasia (3.6\%).

Los cultivares más populares que se exportan siguen siendo el Kent, Tommy Atkins, Haden y Keitt, que son frutas con una coloración roja, poca fibra, firmes y más adecuadas que otras variedades para ser transportadas largas distancias (Sauco 2004). Los cultivares verdes, tales como el Ataulfo y Amelie, están siendo aceptados solo recientemente en el mercado internacional. Otros cultivares que están ganando popularidad en el mercado internacional, incluyen el Alphona, Dudhpeda, Kesar, Sindhu, Pairi, Desi, Chaunsa, Langra y Katchamita. La mayoría de los nuevos cultivares provienen de India y Pakistán.

A través de las décadas, el precio de la mayoría de variedades de mango ha declinado alrededor del 5\% debido al incremento en su disponibilidad mundial, pero este precio se podría mejorar por medio de promociones.

Es evidente que el mercado de mango procesado está creciendo (Sauco 2004). Los productos procesados, incluyen jugo de mango, mangos encurtidos, salsa picante de mango, pulpa de mango, pasta de mango, puré de mango, mango seco, tajadas de mango en salmuera, y harina de mango. India es el mayor exportador de mango procesado, seguido por Pakistán, Brasil y Zimbabwe. Los mayores importadores, incluyen los Emiratos Arabes Unidos, Arabia Saudita, Kuwait, los Estados Unidos, el Reino Unido y Canadá.

\section{Producción, Importación y Consumo de Mango en los Estados Unidos}

Aunque la mayoría de variedades de mangos que se comercian han sido creadas en Florida, Estados Unidos no es un gran productor de mango y su producción ha permanecido más o menos estable debajo de las 3,000 toneladas métricas por año.

Sin embargo, los Estados Unidos es el principal importador de mangos frescos con el $32.7 \%$ del total de importaciones mundiales en el periodo del 2003 al 2005(FAOSTAT 2007). La Figura 1 muestra que las importaciones totales de mango de los Estados Unidos durante ese periodo se incrementaron de 187,193 toneladas métricas a 298,088 toneladas métricas, o un promedio anual de crecimiento del $5.5 \%$. El valor de las importaciones de mango en el 2006 fueron de 233.1 millones de dólares americanos (USDA, Foreign Agricultural Service 2006).

Méjico, Perú, Ecuador y Brasil proveen la mayor parte de las importaciones de mango de los Estados Unidos, con Méjico proporcionando el $60 \%$ de ellas en el 2006 (La Figura 2). Durante los 


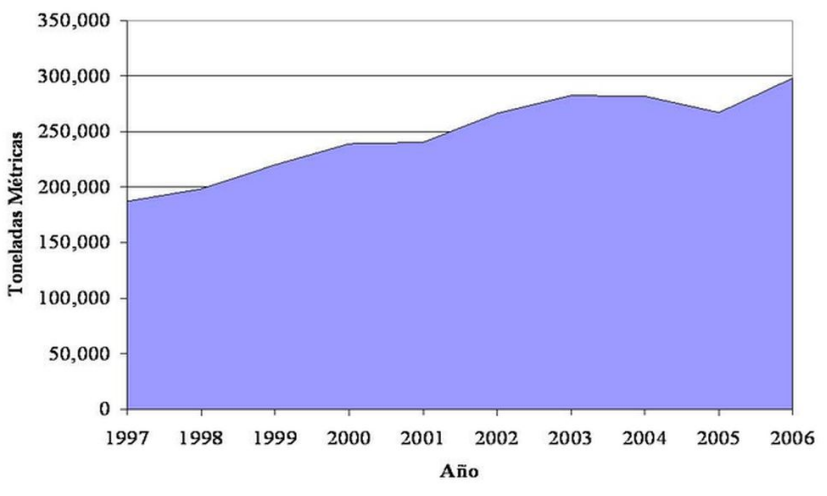

Figure 1. Importaciones de mango de los Estados Unidos, 1997-2006 (toneladas metricas). Fuente: USDA/FAS.

últimos cinco años, Brasil, Perú y Ecuador se han convertido en exportadores importantes hacia los Estados Unidos compitiendo con Méjico al comienzo y al final de la temporada. Los Estados Unidos redistribuye muy poco de sus importaciones de mango hacia otros países, principalmente Canadá y el Reino Unido.

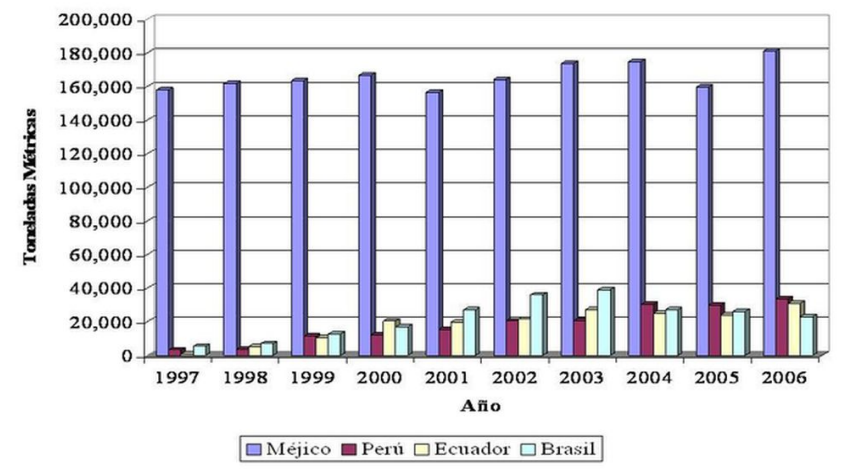

Figure 2. Importaciones de mango de los Estados Unidos, por pais, 1997-2006 (toneladas metricas). Fuente: USDA/FAS.

El consumo de mango en los Estados Unidos ha crecido constantemente de medio kilo por persona en 1996 a un kilo por persona en el 2005 (USDA, Economic Research Service 2006). Este crecimiento se debe a muchos factores tales como disponibilidad durante todo el año, precios bajos, preferencias de los consumidores y mayores ingresos disponibles. Sin embargo, el consumo de mango en los Estados unidos es relativamente bajo si se le compara con el consumo de otras frutas como el del plátano $(11 \mathrm{~kg}$.) y las naranjas $(5 \mathrm{~kg}$.$) .$

Los precios del mango en los Estados Unidos varían bastante de acuerdo al cultivar y a la estación, debido principalmente al hecho de que la demanda es precio inelástica (sensitiva a variaciones en la cantidad disponible. El incremento de $1 \%$ en la cantidad causa una baja de más del $1 \%$ en el precio). En general, los precios del mango han declinado constantemente durante la década pasada. El Cuadro 4 muestra los precios CIF (costo, seguro y flete) promedio del mango que los Estados Unidos importó en el periodo de 1998 al 2006.

\section{Conclusión}

El mango en el mundo se produce en más de 90 paises. Mientras que solo una pequeña proporción de esta producción es comercializada internacionalmente (menos del 4\%), el volumen de este comercio se ha incrementado notablemente durante la última década. Entre los factores responsables por el incremento en la producción, comercialización y consumo de mango están su disponibilidad durante todo el año, menor numero de barreras en el comercio internacional, variedades que después de cosechadas duran más tiempo sin deteriorarse y el interés de los consumidores. Aunque los Estados Unidos no es un productor importante de mangos, ha desarrollado los cultivares más populares en el mercado internacional y es el mayor importador del mundo.

\section{Referencias}

ERS Online. Economic Research Service, United States Department of Agriculture, Washington, D.C. http://www.ers.usda.gov/Data/FoodConsumption/ FoodAvailSpreadsheets.htm

FAOSTAT. 2007. FAO Statistics, Food and Agriculture Organization of the United Nations, Rome, Italy. http://faostat.fao.org/

Sauco, V. 2004. Mango production and world market: Current situation and future prospects. Acta Horticulturae 645: 107-116.

USDA Online. Foreign Agricultural Service, United States Department of Agriculture, Washington, D.C. http://www.fas.usda.gov/ustrade 


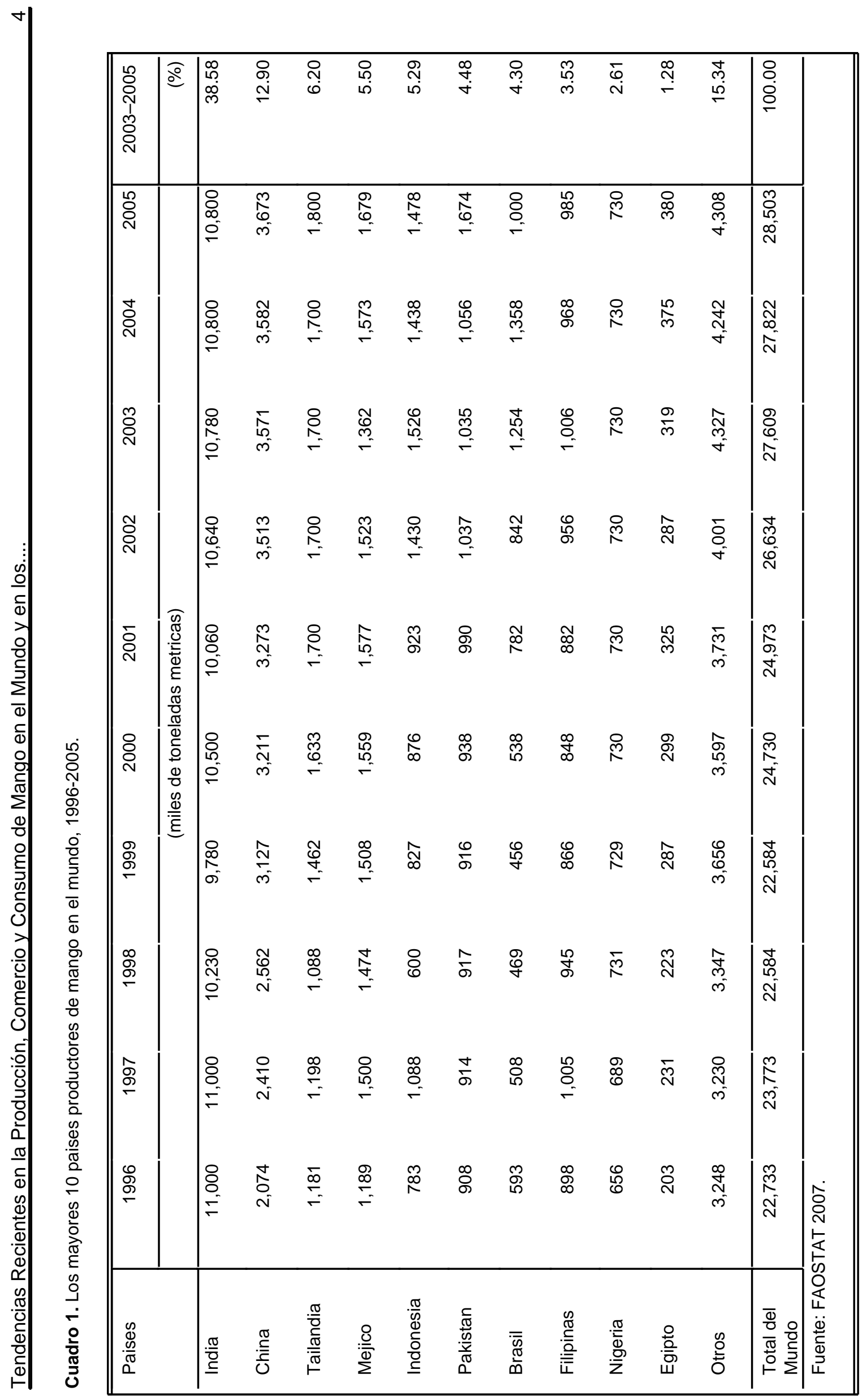




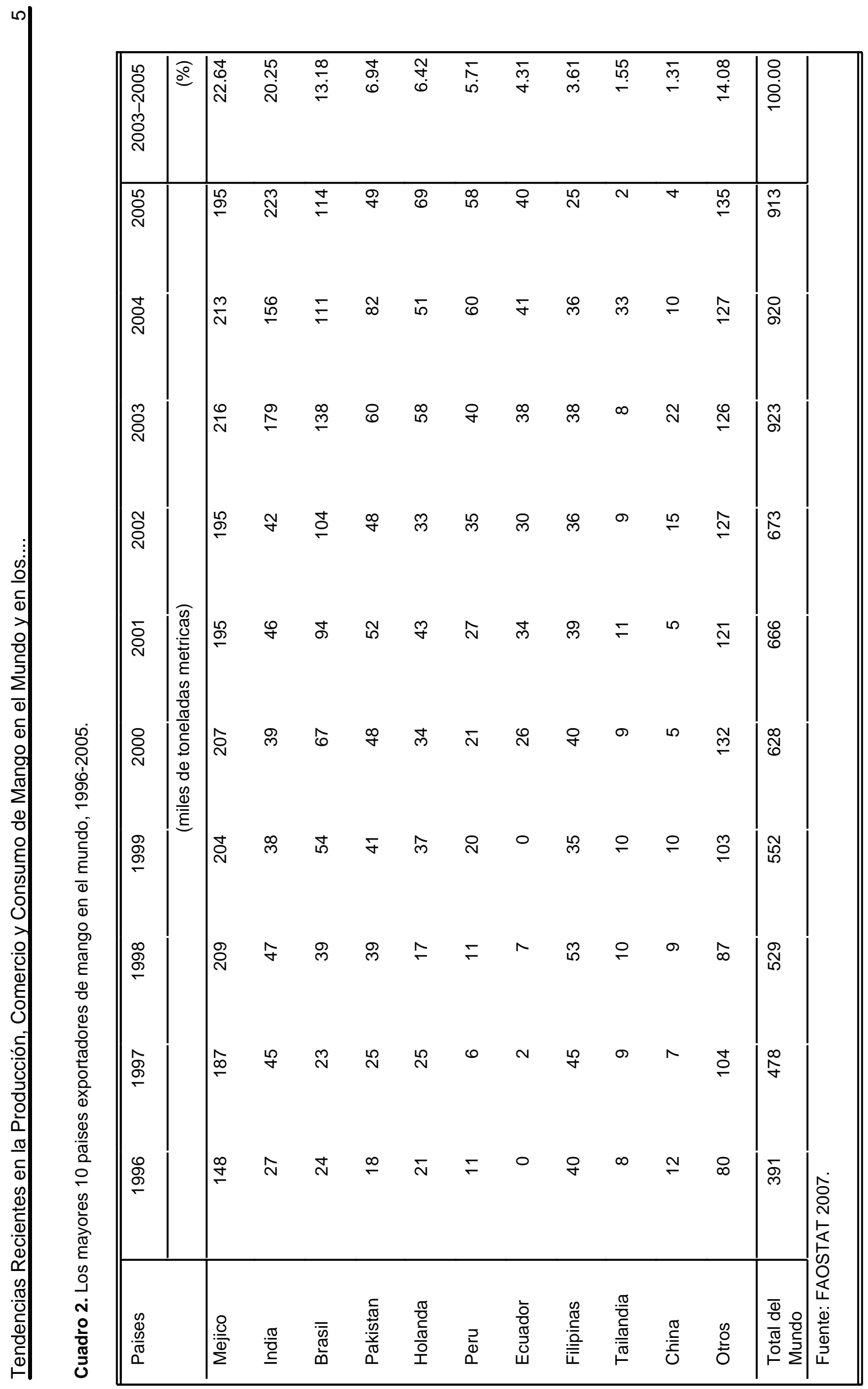




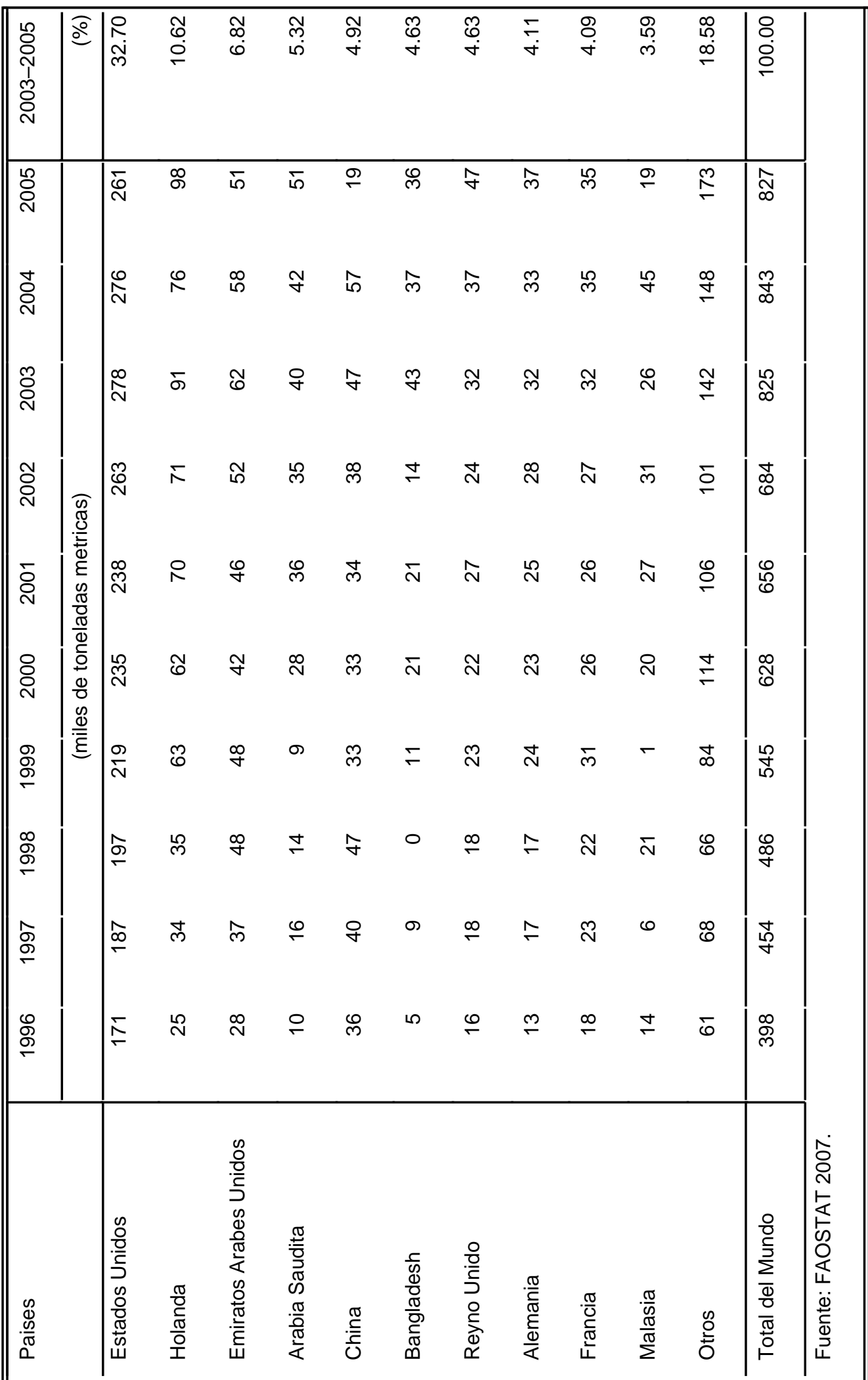




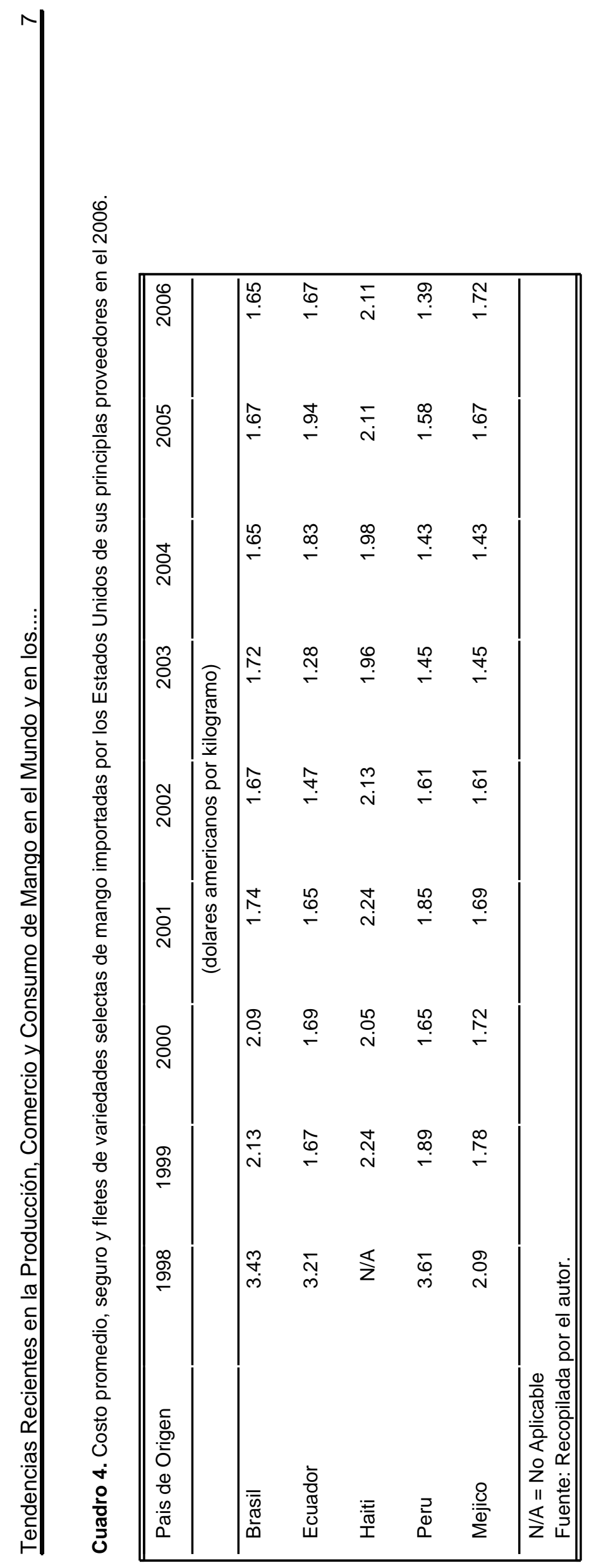

